\title{
The Impact of Interviewer Working Hours on Police Interviews with Children
}

\author{
Marilena Kyriakidou $^{1}$ (D) $\cdot$ Mark Blades $^{2} \cdot$ Julie Cherryman $^{3} \cdot$ Stephanie Christophorou $^{4} \cdot$ Andreas Kamberis $^{5}$
}

(C) The Author(s) 2020

\begin{abstract}
Fatigue resulting from unpredictable or extended working conditions is a factor that negatively impacts the performance of police officers. In this study, we considered how investigative interviewing of children is influenced by interviewer working conditions. We examined two working conditions concerning when interviews were conducted: (a) during early duty shift and (b) an hour before the end of an interviewer's duty shift and after the end of a shift. We analysed 102 police interviews with children and identified clues that interviews which commenced during early duty shift had more appropriate approaches than interviews in the other condition. Inappropriate approaches were not significantly affected by interviewer working conditions. These outcomes suggest considering new knowledge specific to the behaviour of interviewers according to working conditions and provide promising foundations for further research.
\end{abstract}

Keywords Police interview $\cdot$ Cyprus $\cdot$ Children $\cdot$ Forensic $\cdot$ Working hour $\cdot$ Child sexual abuse

\section{Introduction}

Fatigue resulting from unpredictable or extended working hours is a factor that negatively impacts the performance of police officers (Bell et al. 2015; Houdmont and Randall 2016; Scholarios et al. 2017). However, the impact of fatigue on officer performance during police interviews with children is as yet unknown. We therefore conducted our study to examine possible differences in the investigative interviewing of children when an interview was completed within early shift times, compared with when an interview began just before the end of a shift, or when an interviewer was called into work especially to conduct an interview. The outcomes of the study

Marilena Kyriakidou

M.Kyriakidou@shu.ac.uk

1 Department of Psychology, Sociology \& Politics, Sheffield Hallam University, Sheffield, England

2 Department of Psychology, The University of Sheffield, Sheffield, England

3 Department of Psychology, University of Portsmouth, Portsmouth, England

4 Faculty of Psychology and Neuroscience, University of Maastricht, Maastricht, Netherlands

5 Derby University, Derby, England provided support in designing a new policy. One of the aims of this policy was to reduce both the number of interviews conducted just before the end of a shift and interviews conducted during non-working hours. We start this paper by discussing some of the challenges faced by investigative interviewers in eliciting reliable details for prosecution. We then narrow the discussion down to the approaches interviewers use and how these are described in the literature and justify our coding choices. We complete the introduction by addressing situational factors relevant to fatigue that could impact the quality of investigative interviews.

\section{The Challenge}

Child sexual abuse is considered a key public health challenge in Cyprus, where one in five children have allegedly been victims of abuse (Karayianni et al. 2017). Frequently, the only evidence against suspects in child abuse cases is the child's testimony (Frasier and Makoroff 2006). Indeed, for all alleged crimes in which children testified in Cyprus between 2004 and 2009, twothirds had no evidence other than the child's testimony (Kyriakidou 2011). Conducting an investigative interview is a cognitively demanding task and requires police interviewers to be focused and alert throughout the whole of an interview with a child if they are to perform at their best (Milne and Bull 2016). This places pressure on 
investigative interviewers because if children do not provide appropriate information, there is no other evidence on which the case can proceed.

\section{Defining Interviewer Approaches}

Although there is some disagreement between researchers on the details of how best to define question types and interview children, researchers and practitioners generally agree between and among themselves on what constitutes appropriate and inappropriate approaches (Kyriakidou 2017; Oxburgh et al. 2010a). In particular, the Cyprus National Police training and guidelines advise that police interviewers rely on the use of open-ended questions when interviewing children (e.g. 'tell me about John') (Domestic Violence and Child Abuse Office 2007). It is proposed that using the TED (tell, explain, describe) interviewing style and facilitators (such as ' $u$ h hum' and ' $g o$ on') are more favourable and are considered more appropriate approaches than other approaches (Oxburgh et al. 2010a, b). TED approaches are labelled by some researchers (Gagnon and Cyr 2017) and police guidelines (National Institute of Child Health and Human Development NICHD; Orbach et al. 2000) as invitations (e.g. 'tell me everything...'), which are further divided into general (e.g. 'tell me more about...'), cued invitations (e.g. 'you mentioned...tell me more about that') and time segmentation invitations (e.g. 'tell me what happened from ....until...'). Openended questions (like TED, facilitators) gain not only more reliable details, but also longer responses from children (Sternberg et al. 1996). In particular, open-ended approaches seem to extract almost half of all details provided by children in allegations of sexual abuse investigated by police (Lamb et al. 2003). Myklebust and Bjørklund (2010) examined factors that influenced the length of children's responses in 100 field police interviews with children in Norway. Myklebust and Bjørklund found that the different ways interviewers framed their approaches influenced the length of a child's responses. Open-ended questions resulted in children providing on average 38 words, but yes/no questions resulted in an average of only three words.

In contrast, interviewer approaches framed as yes/no questions (e.g. 'was he tall?') and choice questions (e.g. 'was he tall or short?') are considered highly suggestive and therefore inappropriate (e.g. Griffiths and Milne 2006; Oxburgh et al. 2010b; Peterson and Grant 2001). Children tend to answer yes to such questions even if they do not know the answer (Fritzley et al. 2013), or they answer even if the question does not make sense (Waterman et al. 2004). Moreover, when interviewers ask about a detail that the child did not mention, this new topic is likely to be included in the child's subsequent responses. Thus, these approaches are considered leading and inappropriate (Goodman and Schaaf 1997).
Questions still remain about how to categorize some approaches. For example, some wh-approaches (such as when/where/which) are not clearly defined as appropriate or inappropriate by review studies (Oxburgh et al. 2010a). Police guidelines also do not clearly define these wh-approaches as appropriate or inappropriate, for example, 'Achieving Best Evidence' states that wh-approaches '...can be framed as open-ended questions, they are much more commonly used as specific-closed questions' (Ministry of Justice 2011 p.79). Similarly, approaches like 'Can you tell me...?' are labelled sometimes as appropriate (Korkman et al. 2006) and sometimes as inappropriate approaches (Rischke et al. 2011). The present study addresses these disagreements by labelling such approaches as neither appropriate nor inappropriate. Instead, they are labelled as 'neutral' (see coding section).

\section{Situational Factors}

Situational factors impact the criminal justice system, for example judges' lunch breaks or the time of the day a prisoner's request is considered do influence judicial decisions (Danziger et al. 2011). Many situational factors have been adapted with important and immediate outcomes in judiciary deployment (Broadhurst et al. 2018). For example, welfare timetables for children in judicial processes have been introduced, meaning that when a court develops a timetable for any appointments (that involve children) related to a case, the development of the timetable needs to take the child's welfare into consideration, e.g., by avoiding early morning hours (Broadhurst et al. 2018; The Children and Families Act 2014). Still, such situational factors have not been considered for investigative interviewers.

We need to be aware of factors resulting in interviewers deviating from using appropriate approaches. Police officers work non-standard schedules which usually involve working outside the Monday-Friday daytime hours pattern and involve shift work. Such non-standard schedules may be challenging, because these may not always be family friendly hours (Posthuma et al. 2007). Scholarios et al. (2017) surveyed 1207 police officers in the UK on how the unpredictability of their working time (defined by the Scholarios et al. (2017) as both extended working hours and having short notice about the start or end time of a working shift) impacted on their wellbeing. Scholarios et al. (2017) found that the unpredictability of working hours had an effect on police officers' wellbeing, sleep, digestive and cardiovascular health.

In addition to these, recovery or relaxation time off work is important to maintain productivity and a healthy lifestyle. Not continuing work or not being called back into work during non-working hours is essential for a person to relax and recover from the day's workload (ten Brummelhuis and Trougakos 2013; Sonnentag and Niessen 2008). Corresponding to the findings of Scholarios et al. (2017), Houdmont and Randall (2016) found from a survey of UK 
police officers that there was a strong relationship between their long working hours and psychological distress and emotional exhaustion. Additionally, and especially relevant to the present research study, working for longer hours may decrease a person's energy and productivity (Geurts and Sonnentag 2006). Bell et al. (2015) found that US police officers working long shifts (13 to $20 \mathrm{~h}$ ) had an accompanied decrease in their hours and quality of sleep. These police officers performed worse during a STROOP Colour-Word test, indicating a deterioration of their concentration and cognitive processing, compared with police officers on a 10-h shift. Those working the long shifts were more likely to show increased fatigue and have worse reaction times than officers on the $10 \mathrm{~h}$ shifts. It is clear from the existing literature that eagerness to leave work, and other cognitive distractions, can negatively influence an individual's performance (Lee et al. 2014), but the association between fatigue and being eager to leave work and the performance of interviewers of child witnesses has yet to be established. Child abuse cases can be reported at any time of the day and any day of the week. Children need to be interviewed about such crimes as soon after the event as possible, because of concerns about the child's welfare (it may not be safe to let the child return home) or because long delays may result in memory loss of the abuse (Peterson et al. 2005; Quas et al. 2007). Therefore, police interviewers are likely to be asked to stay on longer, or be asked to return to work when off duty, to interview children. When asked to do so, they may not be as effective in their interviewing as when conducting the interview during working hours.

\section{The Present Study}

In this study, we considered how the quality of interviewer performance in forensic interviews with children might be influenced by the interviewer's working hours. Interviewer working hours (e.g. the end of a duty shift) may be at any time of the day. In contrast, 'time of the day' refers to specific times in a solar day. For the purpose of these studies, we perceived 'interviewer working hours' to be a different situational factor than the time of the day. Our main objective addressed how the quality of interviewer approaches is influenced when interviews are conducted in two working conditions: During early duty shift 'working hours', an hour before the end of an interviewer's duty shift 'towards the end' or after the end of a shift 'non-working hours' (combined as 'towards the end and non-working hours').

We analysed the quality of interviews conducted by a range of trained police officers from 2005 to 2018. During this period, all police officers who specialize in interviewing children had to attend national police training and follow the national guidelines on interviewing children (Kyriakidou and Zalaf 2016). In addition, police interviewers were given opportunities to attend training sessions on Achieving Best Evidence
([ABE] Ministry of Justice 2011), Preparation and Planning, Engage and Explain, Account, Closure and Evaluate ([PEACE] (Clarke and Milne 2001) and the guidelines from the National Institute of Child Health and Human Development ([NICHD] Orbach et al. 2000). Experts on PEACE and NICHD from England and Israel have provided training on these. Based on earlier literature (e.g. Houdmont and Randall 2016; Scholarios et al. 2017), our first assumption was that interviews taken towards the end of a working day and during non-working hours would have less appropriate approaches and second, include more inappropriate approaches than interviews taken during working hours. It was unclear how the usage of neutral approaches would be influenced or not across the working conditions.

\section{Methods}

\section{Sample}

In total, 102 interviews were analysed. There were 72 (70.6\%) interviews taken in working hours, 30 (29.4\%) taken in towards the end and non-working hours. This was a national sample (Nicosia (48\%), Limassol (24.5\%), Larnaca (14.7\%), Paphos (6.9\%), Ammochostos (3.9\%) and Morphou (2\%)). There were 54 (90\%) female interviewers and $57(94.1 \%)$ girl interviewees. All interviews investigated child sexual abuse allegations by interviewing the victims of alleged abuse. The average duration of the interviews was $32 \mathrm{~min}(S D=0: 21)$. Children's ages were $M=11.88, S D=3.3$ for working hours; $M=12.34, S D=2.8$ for towards the end and non-working hours. There were no significant differences between the mean ages in the two conditions $F$ $(1,101)=0.449, p=.504$. Interviews in each working condition were treated as independent observations making this a between-subject design.

\section{Coding Interviewer Working Hours}

We categorized the interviews into two working conditions which included interviews taken: (a) during early duty shift (working hours) and (b) an hour before the end of an interviewer's duty shift (towards the end) or after the end of a shift (non-working hours), which combined the towards the end and non-working hours condition due to the small number of interviews taken in the towards the end and non-working hours conditions. To do so, we needed to identify each interviewer's working hours. At the beginning of each interview in Cyprus, interviewers have to state where they are based. Knowing where the interviewers were based, we could identify whether the interviewers worked 'office' hours or worked in shifts. 
The office working hours changed between 2000 and 2017, and the following alterations were implemented by the Cyprus police. Based on the office hours, the working hours of the police were recorded as follows: Working hours from 2000 until 31 August 2009 was Monday to Friday from 07:15 to 14:30 including Thursday afternoon until 18:15. From 1 September 2009 to 31 December 2012, the working hours was Monday to Friday from 07:15 to $14: 30$ including Wednesday afternoon until 18:15. From 2013 to 2016, they were Monday to Friday from 07:00 to 15:00. From 2017 to 2018 , interviewers were divided into two groups working from 07:00 to 19:00 every other day, e.g. one group working from 07:00 to 19:00 on Monday and the second group working from 07:00 to 19:00 on Tuesday.

Non-working hours was hours outside those listed above. Towards the end of a working day was interviews that started $1 \mathrm{~h}$ before the end of the working day. This time range was chosen because (a) before the interview starts, interviewers need to make final preparations that take about 15 to $20 \mathrm{~min}$; (b) the average interview in Cyprus is about $30 \mathrm{~min}$ and (c) after the interview has ended, the interviewer needs to carry out procedures (e.g. signing forms, securing and storing the interview recording) that last for about 15 to $20 \mathrm{~min}$. Commencing an interview within an hour of their expected leaving time would therefore have delayed the interviewer from leaving work on time.

\section{Coding Interviewer Approaches}

The present study focused on the effect of working hours on interviewer performance, so we have coded only interviewer approaches. We decided against coding children's responses because the fact that some children may provide full responses to poor questions does not make the poor questions appropriate. The term 'approaches' was chosen instead of question types as some approaches are not phrased as questions (e.g. 'tell me more about it'), but rather as statements. Thus, the term approaches more accurately describes all verbal communication from the interviewer to the child.

Each transcription was broken into phrases and subphrases. A phrase was a turn in the conversation (Lamb et al. 1996). Sub-phrases were the clauses of those turns identified via commas and conjunctions. For example:

\section{Interviewer: Hello my name is Maria. Tell me about your day so far. \\ Interviewee: It was okay.}

These were considered one phrase for the interviewer with two sub-phrases and one phrase for the interviewee with one sub-phrase. To assess interviewer approaches, we initially coded whether each approach was present or not. Then, the total number of each approach within each interview was noted, leading to numeric variables. Each approach was labelled as appropriate, neutral and inappropriate as shown below. These terms and categorisations are based on Kyriakidou et al. (2020).

\section{Appropriate Approaches}

Appropriate approaches included TED, facilitators and echo which asked children to recall freely an event or to provide open-ended responses (Agnew et al. 2006; Leander et al. 2009; Powell and Hughes-Scholes 2009). TED was noted in any subphrase that included the words 'tell', 'explain' and 'describe' as defined by Myklebust and Bjørklund (2010). TED approaches combined with 'what' and 'how' words were noted as appropriate approaches (e.g. tell me what happened). Facilitators were any vague sounds $u$ h hum and encouragements were any comments encouraging the child to keep talking go on as defined by Myklebust and Bjørklund (2010). Echo-consistent approaches were when interviewers repeated the identical words of the child as a statement (Hershkowitz et al. 2002). However, echoing may take many forms, for example: Interviewee: 'He was big'. When the interviewer replied 'Big', this was coded as an appropriate approach (Hershkowitz et al. 2002) as well as when the interviewer replied 'Tell me how big he was' (Myklebust and Bjørklund 2010). When the interviewer replied 'How big?' this was considered an appropriate approach (Oxburgh et al. 2010a). If the interviewer replied Big? this was considered a yes/no question and was coded as an inappropriate approach (see the section on "Inappropriate Approaches") (Guadagno and Powell 2014). There are in total six wh-approaches which are how, what, when, where, which and who (Oxburgh et al. 2010a). From these six wh-approaches, the how, what, who and why are considered open-ended approaches by most researchers (Oxburgh et al. 2010a, b). Thus, wh-approaches, with the words 'how', 'what', ' $w h o^{\prime}$ and ' $w h y$ ' were coded as appropriate.

\section{Neutral Approaches}

These approaches do impact interviewee responses, labelling them as neutral should not imply they have a minimal impact on an interviewee's responses. Neutral approaches included wh-approaches, with the words 'when', 'where' and 'which', e.g. When did this happen? As these are not clearly classified into appropriate and inappropriate approaches by review studies (e.g. Oxburgh et al. 2010a) and police guidelines (Ministry of Justice 2011), we did not include them in either the appropriate or inappropriate categories but instead looked at the appropriateness of the question overall.

Echo approaches when interviewers repeated the interviewees' words in the form of these wh-approaches (e.g. Interviewee: 'He was big'. Interviewer: 'Who was big?') were considered neutral. Approaches combining yes/no questions with TED approaches (e.g. 'Can you describe 
him more?') were also considered neutral because they were not clearly defined in the literature as appropriate or inappropriate, with some researchers coding these as appropriate (Korkman et al. 2006) and others as inappropriate (Rischke et al. 2011). Indeed, children's answers to such a question could focus on the 'tell me more' part of the question which might then result in the child providing more accurate information, or the child focusing on the ' $\mathrm{Can}$ you' part of the question, which might result in a yes or no response from the child. Thus, approaches combining yes/ no questions with wh- approaches (e.g. 'Can you describe to me how tall he was?') were also considered neutral.

\section{Inappropriate Approaches}

Inappropriate approaches included yes/no and choice questions (Guadagno and Powell 2014). A yes/no question was noted as any sub-phrase that asked interviewees to reply with a simple yes or no, e.g. 'was he tall?'; and choice questions were any questions offering a choice to interviewees e.g. 'was he taller or shorter than me?' as defined by Guadagno and Powell (2014). Echo approaches that were formed as choice approaches (e.g. Interviewer: 'You said earlier he was tall, was he taller or shorter than me?') were also considered inappropriate and where coded as choice questions. Echo approaches that were formed as yes/no approaches (e.g. Interviewee: 'He was tall'. Interviewer: 'Tall?') were coded as yes/no approaches. Approaches that introduced new information that the child had not mentioned earlier were considered leading and therefore inappropriate as suggested (Goodman and Schaaf 1997). Approaches that introduced a new topic were judged as inappropriate no matter how they were phrased. Thus, they may have been phrased as TED or wh-approaches. .

\section{Inter-Rater Reliability}

The principal investigator and a research assistant, who was blind to the study's aim, practised coding until $100 \%$ agreement was found for all the approaches used. The principal investigator due to her qualifications offered training to the research assistant on how to code the interviews based on the coding guidelines of the present paper. Coders practised on one mock police interview (i.e. one used by Cyprus police during their training where an actor acted as a child) and two police interviews with children conducted by the police as part of their regular work. Coders practised until they agreed on how to identify each interviewer's approach within an interview. Twelve per cent of the interviews analysed for study one and two were coded by both coders. Inter-rater reliability was calculated as agreements between the coders and Cohen's kappa ranged from 0.87 to 98 for the approaches. Disagreements were resolved through discussion.

\section{Procedure}

Personal details (e.g. names of children, names of interviewers, home addresses) were not included in the interviews used in this study, and the children's responses have not been analysed. Data collection was conducted in the DV/CA office because the transcriptions could not be removed from that office. To identify the interviews in each working condition, two coders went through all available transcriptions in the DV/CA office and (a) checked the starting time and date that the interview was conducted, (b) checked where the interviewer was based, (c) contacted interviewers who worked in shifts based on where the interviewers were working at the time of the interview, (d) checked the interview was with a child who was an alleged victim in a police investigation about suspected sexual abuse (interviews of cybercrime, neglect, psychological abuse, physical abuse, witnessing murder and other crimes were excluded), (e) confirmed that the child did not have learning disabilities, (f) chose similar age groups across the three conditions ranging from 5 to 17 years old, (g) excluded interviews where the child said s/he had lied in an earlier interview, (h) excluded interviews with translators and (i) excluded interviews for which the starting or end time was not stated, or appeared incorrect (e.g. said to have started at 14:00 and ended at 13:30). The interviews from the working hours condition were randomly selected as there was a big sample of these interviews available. This was not the case for the towards the end and non-working hours condition as only 30 interviews were available which fulfilled our criteria.

\section{Design, Normality Tests, and Data Transformation}

The three working conditions were the independent variables. The approaches used were the dependent variable. Each of the 11 dependent variables was not normally distributed based on a Shapiro-Wilk normality test ( $p>.05$ for each variable). Logarithmic transformation was performed on each dependent variable to normalize their distribution.

\section{Results}

\section{Preliminary Analysis}

We have conducted a Levene's test to assess the equality of variance for each one of the 11 dependent variables between the two working conditions. The variance for each dependent variable in the two working conditions compared was equal, except for the yes/no-wh (Table 1). MANOVA was conducted for the ten variables that met the assumption of homogeneity of variances. Brown-Forsythe test was conducted for the yes/no-wh approaches that did not meet the assumption of 
Table 1 Levene's test: outcomes on the equality of variances for each dependent variable

\begin{tabular}{llrll}
\hline Approaches & $d f 1$ & $d f 2$ & $F$ & $p$ \\
\hline TED (appropriate) & 1 & 99 & 1.1 & .29 \\
Facilitators (appropriate) & 1 & 99 & 0.001 & .97 \\
Echo (appropriate) & 1 & 100 & 0.041 & .84 \\
How/what/who/why (appropriate) & 1 & 100 & 0.096 & .76 \\
Echo/Wh (neutral) & 1 & 77 & 0.31 & .58 \\
When/where/which (neutral) & 1 & 100 & 0.19 & .66 \\
Yes/no-TED (neutral) & 1 & 82 & 0.003 & .95 \\
Yes/no-Wh (neutral) & 1 & 49 & 7.039 & .01 \\
Choice (inappropriate) & 1 & 95 & 2.15 & .45 \\
Leading (inappropriate) & 1 & 100 & 0.92 & .34 \\
Yes/no (inappropriate) & 1 & 100 & 1.56 & .21 \\
\hline
\end{tabular}

homogeneity (Karagöz and Saraçbası 2016; Moder 2007, 2010).

Discriminant function analysis was conducted to test any associations between the children's ages and interviewer approaches (appropriate, neutral, inappropriate). There were no significant associations between children's ages and appropriate approaches (Wilks' $\lambda=0.958, \chi^{2}(6)=4.163, p=.655$ ), neutral approaches (Wilks' $\lambda=0.991, \chi^{2}(3)=0.856$, $p=.836$ ) and inappropriate approaches, (Wilks' $\lambda=0.904$, $\left.\chi^{2}(6)=9.758, p=.135\right)$. Considering these, children's ages were excluded from any further analysis.

\section{Descriptive Information}

In total, the average use of yes/no approaches in the interviews was higher than any other approach used by interviewers $(M=1.77, S D=0.29)$ and the average use of TED approaches in the interviews was $M=0.98(S D=0.45)$. This summary (Table 2) confirms earlier literature where inappropriate approaches such as yes/no approaches typically exceed appropriate approaches such as TED approaches.

\section{Interviewer Approaches in the Working Conditions}

To examine the quality of interviewer approaches (appropriate, neutral, inappropriate) in the three working conditions, we conducted a multivariate analysis of variance (MANOVA) as it allowed us to simultaneously test how each dependent variable varied in the two working conditions. There were significant differences in the use of appropriate $(F(1,100)=23.3$, $\left.p<.001, n^{2}=0.2\right)$ and neutral $(F(1,100)=6.86, p=.010$, $\left.n^{2}=0.06\right)$ approaches, but not in the use of inappropriate approaches $\left(F(1,100)=.406, p=.525, n^{2}=0.004\right)$. The average usage of appropriate, neutral and inappropriate approaches in the working hours condition was $5.71(S D=1.2), 1.8(S D=$ $0.7)$ and $3.41(S D=1.2)$ respectively. The average usage of appropriate, neutral and inappropriate approaches in the towards the end and non-working hours condition was 4.42 $(S D=1.2), 1.4(S D=0.5)$ and $3.26(S D=1.05)$ respectively.

In particular, all sub-categories of appropriate approaches significantly varied between the two working conditions with $\operatorname{TED}\left(\mathrm{F}(1,99)=22.95, p<.001, n^{2}=0.2\right)$, facilitators $\left(\mathrm{F}(1,99)=14.45 .96, p<.001, n^{2}=0.12\right)$, echo $(\mathrm{F}(1,99)=$ $\left.10.05, p=0.02, n^{2}=0.1\right)$ and how $/$ what $/$ who/why $(\mathrm{F}(1$, $99)=5.78, p=.018, n^{2}=0.05$ approaches being higher in the working hours condition than the towards the end and non-working hours condition .

Only when/where/which approaches significantly varied between the two conditions from the neutral approaches category $\left(\mathrm{F}(1,100)=7.86, p=.006, n^{2}=0.1\right)$, and they were significantly higher in the working hours condition than the
Table 2 Mean (SD) of interviewer approaches

\begin{tabular}{|c|c|c|c|c|c|c|c|}
\hline \multirow[b]{2}{*}{ Approaches } & \multicolumn{3}{|c|}{ Total } & \multicolumn{2}{|c|}{$\begin{array}{l}\text { Working } \\
\text { hours }\end{array}$} & \multicolumn{2}{|c|}{$\begin{array}{l}\text { Towards the end-non working } \\
\text { hours }\end{array}$} \\
\hline & $n$ & $M$ & $S D$ & $M$ & $S D$ & $M$ & $S D$ \\
\hline TED (appropriate) & 101 & 0.98 & 0.45 & 1.11 & 0.40 & 0.66 & 0.43 \\
\hline Facilitators (appropriate) & 101 & 1.58 & 0.40 & 1.67 & 0.37 & 1.35 & 0.38 \\
\hline Echo/Statements (appropriate) & 102 & 1.31 & 0.41 & 1.39 & 0.39 & 1.10 & 0.41 \\
\hline How/what/who/why (appropriate) & 102 & 1.49 & 0.32 & 1.54 & 0.30 & 1.36 & 0.30 \\
\hline Echo/Wh (neutral) & 79 & .45 & 0.33 & 0.45 & 0.32 & 0.40 & 0.35 \\
\hline When/where/which (neutral) & 102 & 1.03 & 0.37 & 1.09 & 0.35 & 0.87 & 0.38 \\
\hline Yes/no-TED (neutral) & 84 & 0.25 & 0.25 & 0.26 & 0.25 & 0.21 & 0.24 \\
\hline Yes/no-Wh (neutral) & 51 & 0.26 & 0.27 & 0.26 & 0.29 & 0.27 & 0.20 \\
\hline Choice (inappropriate) & 97 & 0.56 & 0.34 & 0.58 & 0.36 & 0.52 & 0.29 \\
\hline Leading (inappropriate) & 102 & 0.44 & 0.43 & 0.39 & 0.42 & 0.59 & 0.45 \\
\hline Yes/no (inappropriate) & 102 & 1.78 & 0.29 & 1.79 & 0.31 & 1.74 & 0.25 \\
\hline
\end{tabular}


towards the end and non-working hours condition. The means and standard deviations of each approach (e.g. TED, leading) within the working conditions are shown on Table 2. BrownForsythe test showed no significant differences in the use of yes/no-wh approaches in the two working conditions BrownForsythe $F(1,100)=.466, p=.497$.

\section{Discussion}

Although many studies have investigated the quality of police interviews with children (e.g. Wolfman et al. 2016), there seems to be limited interest in situational factors that may impact the quality of such interviews. This is important as situational factors may help explain and improve the quality of police interviews with children. In this study, we analysed police interviews from the Republic of Cyprus, conducted between 2005 and 2018. We explored whether interviewer working hours influenced the quality of interviewer approaches towards children who were alleged victims of sexual abuse.

We have identified clues that working hours may impact the quality of an interviewer's appropriate and neutral approaches, but there was no impact on an interviewer's inappropriate approaches. In particular, fatigue and/or eagerness to leave work may have a negative influence on police interviewer performance as interviews taken in non-working hours or towards the end of a working shift had the lowest number of appropriate approaches. The most important conclusion of this study is that it provides the foundations for further studies to explore whether interviewer behaviour changes unfavourably in the towards the end and non-working hours condition.

\section{Appropriate Approaches Based on Interviewer Working Hours}

The analogy of appropriate and inappropriate approaches used by interviewers in Cyprus is in agreement with the amount of appropriate and inappropriate approaches used by interviewers in other countries such as Australia (Hamilton et al. 2016), Canada (Gagnon and Cyr 2017), Estonia (Kask 2012), Finland (Korkman et al. 2006), New Zealand (Wolfman et al. 2016), Norway (Thoresen et al. 2006) and Sweden (Cederborg et al. 2000). Thus, the quality of police interviews in Cyprus is similar to those in other countries. However, when considering the time the interview was conducted based on interviewer working schedules, it seems that this situational factor is likely to affect an interviewer's interviewing performance.

This contributes to the existing literature by providing clues that appropriate approaches may increase under specific environmental circumstances. If further studies confirm this outcome, it can be a positive factor for investigations. Appropriate approaches can lead to reliable details being obtained as children have a propensity to be more truthful when answering such questions (Sternberg et al. 1996). Children also tend to elaborate on their answers when answering appropriate approaches (Myklebust and Bjørklund 2010), something that can help the police extract more details regarding an investigation.

A question raised by this outcome is why working hours might influence the phrasing of appropriate approaches but not the phrasing of inappropriate approaches. Perhaps appropriate approaches require more cognitive resources and therefore are affected more by working hours and consequently fatigue. Phrases used regularly or naturally, are cognitively less demanding (Gundel et al. 1993). Daily conversations rely mostly on inappropriate approaches such as 'Did you have a good day?' instead of appropriate approaches 'Describe your day to me' (Hester 2016). The common use of inappropriate approaches may make them cognitively less demanding and more easily generated in different contexts (e.g. investigative interviews). Police officer concentration and cognitive processes deteriorate the longer they stay at work (Bell et al. 2015). Consequently, as fatigue impacts interviewer cognitive processes, appropriate approaches may decline if they require more cognitive effort than other approaches. Further research is needed to assess this proposition.

\section{Neutral Approaches Based on Interviewer Working Hours}

Characterizing some interviewer approaches as neutral is a new categorisation in the literature of forensic interviewing. The main reason behind this decision was to tackle the challenges described in Oxburgh et al. (2010a) regarding approaches that are not clearly labelled as appropriate or inappropriate among researchers. Oxburgh et al. (2010a) suggested considering both the phrasing and function of approaches used. Placing these approaches in a neutral category was seen as necessary following the conclusions of Oxburgh et al. (2010a) and the unclear categorisation of such approaches into appropriate or inappropriate in national police manuals (Ministry of Justice 2011).

By doing so, it enabled us to study interviewer behaviour solely on those neutral approaches. The outcomes that emerged as significant were that the number of neutral approaches used, in particular when/where/which, was noticeably higher in the working hours condition in comparison with the towards the end and non-working hours condition. Interviews with a low number of when/where/ which approaches can be detrimental in criminal investigations as they are less likely to extract important details. Wh-approaches can extract fundamental information regarding an alleged crime (Milne and Bull 2006). Fatigue experienced via the different working conditions can be a 
factor to be considered in avoiding interviews with a low number of when/where/which approaches.

\section{Limitations}

Despite the many strengths of this work, the findings should not be interpreted as evidence to inform any policies but should provide promising directions for future research.

Coding children's responses would have provided a stronger case for how interviewer working conditions impact the quality of interviews. As this study was the first study to investigate the impact of interviewer working hours on their interviewing performance in child abuse cases, we focused only on interviewer approaches. We believe this decision to be valid, because an inappropriate interview approach cannot change to being an appropriate approach as a result of a child's response. Even if, for example, a child resists a leading question and provides adequate detail, the leading question remains an inappropriate interview approach and this might be detrimental to the prosecution of a case.

Coding interviewer performance at the overall level and then testing how this performance is affected by working conditions would have added further to this study. However, this was not possible due to the General Data Protection Regulation 2016/679 and the way the police interviews were coded.

The average use of each approach (e.g. TED, leading) was similar between the two conditions even for the approaches that were judged to be significantly higher in the working hours condition and with large effect sizes. To clarify if there are any notable and meaningful differences between interviewer working conditions, further studies are needed.

\section{Policy-Making: Impact of the Present Work to the Police}

Cyprus Police were informed about the outcomes of this study via both personal communication in 2017 and a report (Kyriakidou 2018). The study outcomes were among the factors that were taken into consideration by the police in assessing, designing, preparing and implementing the Investing in the Good Interviewers policy of practice (IGIpop). IGIpop was applied in Cyprus in January 2017. Details on the IGIpop as well as how the interviewers were chosen are in Kyriakidou et al. (2020). With IGIpop, the chances of conducting interviews towards the end and non-working hours have been reduced. After IGIpop implementation, all interviews regarding sexual abuse allegations are conducted by the 'good' interviewers working every other day in shifts including weekends in an effort to reduce the number of interviews taken in non-working hours or towards the end of a working shift.

A pilot study showed that the IGIpop succeeded in reducing the interviews conducted during non-working hours and towards the end of a working shift (Kyriakidou 2020). This seemed to be a positive step forward for the police. The same pilot study showed that the IGIpop interviewers maintained their good performance across all working conditions. The positive influence of the IGIpop on the quality of police interviews with children is discussed in Kyriakidou et al. (2020).

The effects of fatigue and eagerness to leave work on interviewer performance could be considered in making decisions about which interviewer to choose when conducting an interview with a child. We do not suggest delaying an interview. Delaying a police interview with a child regarding child abuse may result in poorer recall (Peterson et al. 2005; Quas et al. 2007), so we suggest interviewing a child immediately after they report abuse, but doing so by choosing an interviewer most likely to be more productive based on the interviewer's working hours. The selection process should consider the working hours of all available interviewers. For example, if several interviewers are available to take an interview then interviewers who are in the early hours of their working shift should be preferred.

\section{Conclusions}

Simply put, we may start considering situational factors (such as interviewer working hours) as likely to impact the quality of forensic interviews with children. It is welcoming the consideration of the present outcomes in designing the IGIpop. As a result, the quality of police interviews with children is now notably improved (Kyriakidou et al. 2020). Having enough time to conduct an interview without rushing or tiredness should help an 'average' interviewer. Interviewers will be able to dedicate more time to encouraging children to talk and be able to give greater focus on how to phrase their approaches. If the results of the present study are proven true via further studies, we should consider appropriate choices of interviewers based on their working hours which can be managed easily without additional training or expense for a police force. If such measures are put into practice, they would increase the likelihood of obtaining better quality evidence from child victims.

Acknowledgments We would like to acknowledge the support of Cyprus Police. Many thanks to Mr. Kosta Veis, the Head of Child Abuse and Domestic Violence Office of the police, for his valuable advices, for hosting us in their premises, for his guidance, and for providing feedback on the present paper. Our gratitude also expands to all the police officers who patiently answered our questions and helped us to carry out this study.

\section{Compliance with Ethical Standards}

Conflict of Interest The authors declare that they have no conflict of pecuniary or other personal interest in any matter that raises conflicts in conducting and preparing the present study.

Ethical Approval This research was ethically approved by Coventry University and the Cyprus Police. 
Informed Consent Not applicable. The data (police interviews) were analysed in an effort to improve police training and the police services.

Open Access This article is licensed under a Creative Commons Attribution 4.0 International License, which permits use, sharing, adaptation, distribution and reproduction in any medium or format, as long as you give appropriate credit to the original author(s) and the source, provide a link to the Creative Commons licence, and indicate if changes were made. The images or other third party material in this article are included in the article's Creative Commons licence, unless indicated otherwise in a credit line to the material. If material is not included in the article's Creative Commons licence and your intended use is not permitted by statutory regulation or exceeds the permitted use, you will need to obtain permission directly from the copyright holder. To view a copy of this licence, visit http://creativecommons.org/licenses/by/4.0/.

\section{References}

Agnew SE, Powell MB, Snow PC (2006) An examination of the questioning style of police officers and caregivers when interviewing children with intellectual disabilities. Leg Criminol Psychol 11:35-53

Bell LB, Virden TB, Lewis DJ, Cassidy BA (2015) Effects of 13-hour 20minute work shifts on law enforcement officers' sleep, cognitive abilities, health, quality of life and work performance: the Phoenix study. Police Q 18(3):293-337

Broadhurst K, Budd T, Williams T (2018) The Nuffield family justice observatory for England and Wales: making it happen. The Nuffield Foundation, England

Cederborg A, Orbach Y, Sternberg KL, Lamb ME (2000) Investigative interviews of child witnesses in Sweden. Child Abuse Negl 24: $1355-1361$

Children and Families Act (2014). Department for Education. Retrieved from http://www.legislation.gov.uk/ukpga/2014/6/contents/enacted

Clarke C, Milne R (2001) National evaluation of the PEACE investigative interviewing course. Police research award scheme. Report NO: PRAS/149. National Crime Faculty, London

Danziger S, Levav J, Avnaim-Pesso L (2011) Extraneous factors in judicial decisions. PNAS 108(17):6889-6892

Domestic Violence and Child Abuse Office (2007) Domestic violence: police guidelines. Cyprus Police, 2007

Frasier LD, Makoroff KL (2006) Medical evidence and expert testimony in child sexual abuse. Juv Fam Court J 57(1):41-50

Fritzley VH, Lindsay CL, Lee K (2013) Young children's responses tendencies towards yes-no questions concerning actions. Child Dev 84(2):711-725

Gagnon K, Cyr M (2017) Sexual abuse and preschoolers: forensic details in regard to question types. Child Abuse Negl 67:109-118

Geurts SAE, Sonnentag S (2006) Recovery as an explanatory mechanism in the relation between acute stress reactions and chronic health impairment. Scand J Work Environ Health 32:482-492

Goodman GS, Schaaf JM (1997) Over a decade of research on children's eyewitness testimony: what have we learned? Where do we go from here? Appl Cogn Psychol 11:5-20

Griffiths A, Milne R (2006) Will it all end in tiers? Police interviews with suspects in Britain. In: Williamson TA (ed) Investigative interviewing: rights, research, regulation. Willan, Cullompton

Guadagno BL, Powell MB (2014) An examination of the prevalence of temporally leading questions in child witness interviews. Int J Police Sci Manag 16(1):16-25

Gundel J, Hedberg N, Zacarski R (1993) Cognitive status and the form of referring expressions in discourse. Language 69(2):274-307
Hamilton G, Brubacher SP, Powell MB (2016) Investigative interviewing of aboriginal children in cases of suspected sexual abuse. J Child Sexual Abus 25(4):363-381

Hershkowitz I, Orbach Y, Lamb ME, Sternberg KJ, Horowitz D (2002) A comparison of mental and physical context reinstatement in forensic interviews with alleged victims of sexual abuse. Appl Cogn Psychol 16(4):429-441

Hester S (2016) Answering questions instead of telling stories: everyday breaching in a family meal. J Pragmat 102:54-66

Houdmont J, Randall R (2016) Working hours and common mental disorder in English police officers. Occup Med 66(9):713-718

Karagöz D, Saraçbası T (2016) Robust Brown-Forsythe and robust modified Brown-Forsythe ANOVA tests under heteroscedasticity for contaminated Weibull distribution. Rev Colombiana de Estadística 39(1):17-32

Karayianni E, Fanti KA, Diakidou I-A, Hadjicharalambous M-Z, Katsimicha E (2017) Prevalence, contexts, and correlates of child sexual abuse in Cyprus. Child Abuse Negl 66:41-52

Kask K (2012) Dynamics in using different question types in Estonian police interviews of children. Appl Cogn Psychol 26:324-329

Korkman J, Santtila P, Sandnabba NK (2006) Dynamics of verbal interaction between interviewer and child in interviews with alleged victims of child sexual abuse. Scand J Psychol 47(2):109-119

Kyriakidou M (2011) Evaluation of children's testimonies in the Republic of Cyprus: implications for criminal and legal procedures. The University of Sheffield: $\mathrm{PhD}$ Thesis

Kyriakidou M (2017) Questioning, police manuals and quantisation. International Investigative Interviewing Conference. Held 5-7 July 2017 in California, United States

Kyriakidou M (2018) Reporting on studies and training conducting in summer 2017 in the Domestic Violence and Child Abuse (DVCA) Office in Cyprus Police. Unpublished report: Cyprus Police, Nicosia, Cyprus

Kyriakidou M (2020) The impact of working hours to IGIpop interviewers. Report submitted to Cyprus Police, Domestic Violence and Child Abuse Office

Kyriakidou M, Zalaf A (2016) Transcribing the first decade of children's videotaping testimonies in Cyprus: tourist season times. J Investig Psychol Offender Profiling 13:267-276

Kyriakidou M, Blades M, Cherryman J, Christophorou S, Kamperis A (2020) The impact of investing in the good interviewers policy of practice (IGIpop) on police interviews with children. Police Pract Res. https://doi.org/10.1080/15614263.2020.1712201

Lamb ME, Hershkowitz I, Sterneberg KJ, Esplin PW, Hovav M, Manor T, Yudilevitch L (1996) Effects of investigative utterance types on Israeli children's responses. Int J Behav Dev 19(3):627-637

Lamb ME, Sternberg KJ, Orbach Y, Esplin PW, Stewart H, Mitchell S (2003) Age differences in young children's responses to openendedinvitations in the course of forensic interviews. J Consult Clin Psychol 71(5):926-934

Leander L, Granhag PA, Christianson A (2009) Children's reports of verbal sexual abuse: effects of police officers interviewing style. Psychiatry Psychol Law 16(3):340-354

Lee JJ, Gino F, Staats BR (2014) Rainmakers: why bad weather means good productivity. J Appl Psychol 99(3):504-513

Milne R, Bull R (2006) Interviewing victims of crime, including children and people with intellectual difficulties. In: Kebbell MR, Davies GM (eds) Practical psychology for forensic investigations. Wiley, Chichester, pp 7-23

Milne B, Bull R (2016) Witness interviews and crime investigation. In: Groome D, Eysenck M (eds) An introduction to applied cognitive psychology, 2nd edn. Psychology Press, London, pp 175-196

Ministry of Justice (2011) Achieving best evidence in criminal proceedings: guidance on interviewing victims and witnesses, and guidance on using special measures. Ministry of Justice, London 
Moder K (2007) How to keep the type I error rate in ANOVA if variances are heteroscedastic. Austrian J Stat 36(3):179-188

Moder K (2010) Alternatives to F-test in one way ANOVA in case of heterogeneity of variances (a simulation study). Psychol Test Assess Model 52(4):343-353

Myklebust T, Bjørklund RA (2010) Factors affecting the length of responses in field investigative interviews of children (FIIC) in child sexual abuse cases. Psychiatry Psychol Law 17(2):273-289

Orbach Y, Hershkowitz I, Lamb ME, Sternberg KJ, Esplin PW, Horowitz D (2000) Assessing the value of structured protocols for forensic interviews of alleged abuse victims. Child Abuse Negl 24:733-752

Oxburgh GE, Myklebust T, Grant T (2010a) The question of question types in police interviews: a review of the literature from a psychological and linguistic perspective. Int J Speech Lang La 17(1):45-66

Oxburgh GE, Ost J, Cherryman J (2010b) Police interviews with suspected child sex offenders: does the use of empathy and question type influence the amount of investigation relevant information obtained? Psychol Crim Law Forum 18(3):259-273

Peterson C, Grant M (2001) Forced-choice: are forensic interviewers asking the right questions? Can J Behav Sci 33:118-127

Peterson C, Pardy L, Tizzard-Drover T, Warren KL (2005) When initial interviews are delayed a year: effect on children's 2-year recall. Law Hum Behav 29(5):527-541

Posthuma RA, Maertz CP Jr, Dworkin JB (2007) Procedural justice's relationship with turnover: explaining past inconsistent findings. $\mathrm{J}$ Organ Behav 28:381-398

Powell MB, Hughes-Scholes CH (2009) Evaluation of the questions used to elicit evidence about abuse from child witnesses: Australian study. Psychiatry Psychol Law 16(3):369-378

Quas JA, Lindsay CM, Melinder A, Goodman GS, D’Mello M, Schaaf J (2007) Developmental differences in the effects of repeated interviews and interviewer bias on young children's event memory and false reports. Dev Psychol 43(4):823-837
Rischke AE, Roberts KP, Price HL (2011) Using spaced learning principles to translate knowledge into behaviour: evidence form investigative interviews of alleged child abuse victims. J Police Crim Psychol 26(1):58-67

Scholarios D, Hesselgreaves H, Pratt R (2017) Unpredictable working time, well-being and health in the police service. Int J Hum Resour Manag 28(16):2275-2298

Sonnentag S, Niessen C (2008) Staying vigorous until work is over: the role of trait vigour, day-specific work experiences and recovery. $\mathrm{J}$ Occup Organ Psychol 81:435-458

Sternberg KJ, Lamb ME, Hershkowitz I, Esplin PW, Redlich AD, Sunshine N (1996) The relation between investigative utterance types and the informativeness of child witnesses. J Appl Dev Psychol 17:439-451

ten Brummelhuis LL, Trougakos JP (2013) The recovery potential of intrinsically versus extrinsically motivated off-job activities. J Occup Organ Psychol 87(1):177-199

Thoresen C, Lønnum K, Melinder A, Stridbeck U, Magnussen S (2006) Theory and practice in interviewing young children: a study of Norwegian police interviews 1985-2002. Psychol Crime Law 12(6):629-640

Waterman AH, Blades M, Spencer C (2004) Indicating when you do not know the answer: the effect of question format and interviewer knowledge on children's 'don't know' responses. Br J Dev Psychol 22:335-348

Wolfman M, Brown D, Jose P (2016) Taking stock: evaluating the conduct of forensic interviews with children in New Zealand. Psychol Crime Law 22(6):581-598

Publisher's Note Springer Nature remains neutral with regard to jurisdictional claims in published maps and institutional affiliations. 